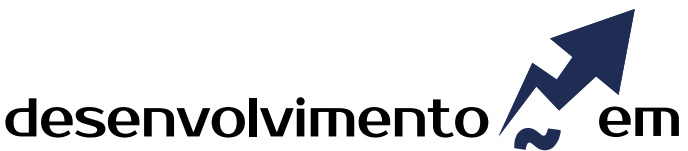 QUESTÃO
}

\section{Representações Sociais e Pobreza no Planalto Norte Catarinense: Voz das Beneficiárias do Programa Bolsa Família}

http://dx.doi.org/10.21527/2237-6453.2019.46.199-217

Recebido em: $31 / 10 / 2016$

Aceito em: 16/8/2018

\author{
Maria Luiza Milani ${ }^{1}$, Pollyana Weber da Maia Pawlowytsch²
}

\begin{abstract}
RESUMO
O objetivo do estudo foi o de analisar as representações sociais dos sujeitos sobre sua condição de pobreza bem como suas implicações no desenvolvimento do Planalto Norte Catarinense. Na realização de pesquisa exploratória com 115 mulheres beneficiárias do Programa Bolsa Família, residentes nos municípios de Mafra, São Bento do Sul, Três Barras e Irineópolis, constatou-se que as pesquisadas entendiam a pobreza a partir de uma visão multidimensional, para a qual a ausência de renda não é o único fator considerado provocador desta condição. Como principais resultados pôde-se apontar que a pobreza foi amplamente assumida pelas entrevistadas com o sentido da privação de liberdade; que na região do Planalto Norte Catarinense os discursos conseguiram fazer uma relação do seu desenvolvimento pessoal com o desenvolvimento de seu lugar - o município. Outro fator relevante nos discursos sobre o desenvolvimento que as entrevistadas conseguiram identificar foi de que o Programa Bolsa Família, mesmo nas condições objetivas de sua concessão, as colocaria em condição melhor do que de outras pessoas. Haveria então alguma inclusão social, pois as entrevistadas sentiam-se atendidas em suas demandas. Concluiu-se então que os aspectos que favoreceriam o desenvolvimento da região também estariam relacionados com a sensação de liberdade de escolhas e de envolvimento social de seus sujeitos, permitindo que estes se identificassem ativos no processo de autodesenvolvimento com o desenvolvimento de sua região.
\end{abstract}

Palavras-chave: Pobreza. Representações sociais. Desenvolvimento regional.

\section{SOCIAL REPRESENTATIONS AND POVERTY IN THE NORTH PLATEAU OF SANTA CATARINA: VOICE OF BENEFICIARIES OF THE BOLSA FAMÍLIA PROGRAM}

\begin{abstract}
The objective of the study was to analyze the social representations of the subjects about their condition of poverty as well as its implications for the development of the PNC. In carrying out an exploratory research with 115 women beneficiaries of the PBF, living in the municipalities of Mafra, São Bento do Sul, Três Barras and Irineópolis, it was verified that the respondents understood poverty from a multidimensional view, for which the absence of income is not the only factor considered to be provocative of this condition. As main results, it could be pointed out that poverty was widely assumed by those interviewed with the sense of deprivation of liberty; that in the region of Planalto Norte Catarinense, the discourses managed to make a relation of their personal development with the development of their place - municipality. Another relevant factor in the development discourses that the interviewees were able to identify, that is, the PBC even under the objective conditions of its concession would put them in a better condition than other people. There would then be some social inclusion, because the interviewees felt they were met in their demands. It was concluded that the aspects that would favor the development of the region would also be related to the feeling of freedom of choices and social involvement of its subjects, allowing them to identify assets in the process of their self-development with the development of their region.
\end{abstract}

Keywords: Poverty. Social representations. Regional development.

\footnotetext{
${ }^{1}$ Doutora em Serviço Social pela Pontifícia Universidade Católica de São Paulo (PUC-SP). Professora do Programa de Mestrado em Desenvolvimento Regional da Universidade do Contestado (UnC). marialuiza@unc.br

${ }^{2}$ Mestre em Desenvolvimento Regional pela Universidade do Contestado (UnC). Professora da Universidade do Contestado (UnC). pollyana@unc.br
} 
O estudo tratou da pobreza existente no Planalto Norte Catarinense (PNC), destacando as representações sociais dos beneficiários do Programa Bolsa Família (PBF) e as implicações para o desenvolvimento regional daquela região.

Considerou-se que a pobreza tem atraído a atenção e preocupações dos estudos e análises sobre a desigualdade de renda, a inclusão e exclusão social, bem como sobre os persistentes índices de sua elevação histórica. Nesse sentido, a pobreza no Brasil passou a ser mais observada especialmente entre 1977 e 1998. Foram as análises das Pesquisas Nacionais por Amostragem de Domicílios (Apnad), realizadas pelo Instituto Brasileiro de Geografia e Estatística (IBGE), que tornaram possível formar diversificado conjunto de indicadores sociais com o objetivo de retratar a distribuição de renda ou os padrões de vida dos sujeitos desta sociedade.

Com isso, os resultados da pobreza no Brasil foram visualizados pelo reconhecimento de que a condição de miséria no país era vivida por mais de 16,27 milhões de pessoas na época deste estudo, ou seja, o equivalente a $8,5 \%$ da população (BRASIL, 2010). Por isso foi possível identificar a responsabilidade social do Estado, a realidade do desemprego, as interferências da baixa escolaridade, de um lado. De outro, as oportunidades para capacitação profissional e a exclusão de segmentos populacionais. A autorresponsabilidade, porém, manifestada pelo próprio sujeito, é representada pela sua baixa estima, desvalorização pessoal, falta de autoconfiança do sujeito e da discriminação sofrida pelos segmentos classificados como pobres ou miseráveis, presente no cotidiano da sociedade brasileira.

Com esse cenário e pelos dados e indicadores foram constituídas políticas públicas e concebidos programas sociais, desde a década de 90 , visando ao enfrentamento da pobreza. Entre os mais relevantes nesse contexto destaca-se a concepção do Programa Bolsa Família (PBF), em 2003, que foi uma conjugação de outros programas de transferência de renda vigentes.

O Bolsa Família é um programa de transferência direta de renda, vigente, que beneficia famílias em situação de pobreza e de extrema pobreza no Brasil desde o ano de 2003. O Planalto Norte Catarinense apresenta um total de 34.612 famílias inscritas no Bolsa Família (PBF), representando um percentual de 9,69\% da população total da região (BRASIL, 2010).

No Brasil, a linha de pobreza foi delimitada pelo critério renda. Para o benefício do Programa Bolsa Família considerou-se as famílias com renda per capita de até $\mathrm{R} \$ 140,00$ (afirmação baseado no valor vigente no ano de 2013). A identificação das famílias pobres e extremamente pobres resulta da soma dos valores dos recursos monetários - renda percebidos pelos integrantes do grupo familiar no domicílio. A totalidade da renda familiar obtida era dividida pelo número total de membros do grupo familiar. A categorização como pobre ou extremamente pobre, nesse período (2013), seguia os seguintes critérios de elegibilidade: se a renda média fosse de até $R \$ 70$, a família é considerada extremamente pobre e recebia o benefício básico de $\mathrm{R} \$ 68$ e, se tivesse crianças e adolescentes de 5 a 15 anos na escola, receberia mais $R \$ 22$ para cada um, num limite de até três pessoas por família. Ainda, se tivesse adolescentes entre 15 e 17 frequentando escola, ao valor da renda percebida pela transferência do PBF, deveria ser acrescido o valor de mais $\mathrm{R} \$ 33$ para cada familiar nessa faixa etária e nessa condição. A soma de valores provenientes da condição de pobreza nesse recorte poderia atingir o valor máximo de até $\mathrm{R} \$$ 
200,00, com a permanência de cinco pessoas na escola (BRASIL, 2013). Para o segmento delimitado pobre, o critério de elegibilidade das famílias era a renda per capita entre $\mathrm{R} \$$ 70,00 e $\mathrm{R} \$ 140,00$, eram beneficiados com valor variável, de acordo com o total de membros da família na escola, atingindo um limite máximo de $R \$ 306,00$ (BRASIL, 2013).

No ano de 2017 os valores passaram por ajustes e o critério de elegibilidade passou a considerar famílias em condição de pobreza extrema aquelas cuja renda per capita atingia o valor de até $\mathrm{R} \$ 85,00$. E as famílias designadas como pobres passaram a ser aquelas cuja renda per capita circulava entre $R \$ 85,01$ e $R \$ 170,00$ mensais, desde que tivessem crianças e adolescentes com idades entre zero e 17 anos (BRASIL, 2017).

Nesse ano de 2017 os valores foram definidos tendo em vista critérios de concessão por faixa etária de membros familiares, a saber: valor passou a ser variável conforme a faixa etária das crianças e adolescentes das famílias: Bolsa Básica - famílias com pobreza extrema: valor fixo concedido de $\mathrm{R} \$ 85,00$, independente da quantidade de filhos; bolsa de 0 a 6 meses: famílias pobres com bebês de 0 a 6 meses -6 parcelas no valor de $\mathrm{R} \$$ 39,00 por bebê (limite máximo de 5 bebês por família); bolsa de 0 a 15 anos de idade: famílias com crianças de 0 a 15 anos de idade - valor de $\mathrm{R} \$ 39,00$ por criança (limite de 5 crianças por família); bolsa de 16 a 17 anos de idade: famílias pobres com adolescentes de 16 a 17 anos - valor de $R \$ 46,00$ mensais por adolescente (limite de 2 adolescentes por família). Desse modo o valor final - máximo - por família é calculado caso a caso (BRASIL, 2017).

Entre as contradições e polêmicas em torno da pobreza, bem como da recente visibilidade que esse cenário evidencia, esta emerge como um fenômeno social e como um compromisso de seu enfrentamento, mas não sem lacunas nos estudos, análises e intervenções. Por isso, o estudo apresentado neste texto é um pequeno recorte que se voltou para o enfoque subjetivo da pobreza, evidenciado na concepção e manifestado na exposição discursiva do sujeito, tendo como respaldo o reconhecimento dos critérios formais e sociais do ser pobre, ou seja, aqueles que, por critério e por processo interventivo para a inclusão social, tornaram-se beneficiários do PBF.

Assim sendo, a concepção de pobreza e do cenário do seu reconhecimento levou ao estudo do ambiente no qual os sujeitos em condição de pobreza estão inseridos e desse ambiente extrair a autolocalização e percepção de sua exclusão, segregação social, bem como o autorreconhecimento de sua capacidade de enfrentamento.

Desta forma, pode-se entender que a existência de situações de pobreza pode provocar um círculo de ruptura e isolamento pelo qual o pobre passa a ser visto pela sociedade, reconhecido apenas como alguém vulnerável, humilhado, destituído de dignidade, de igualdade de oportunidades, autonomia, também a pobreza é responsabilizada pela ausência constante de participação social.

Diante desses breves indicativos, recortados da amplitude do estudo realizado, constatou-se também que o aumento da pobreza na sociedade capitalista decorreu das mudanças em seus padrões de desenvolvimento, quando os programas de transferência de renda (desenvolvidos a partir de políticas públicas) apresentaram-se como estratégia do Estado para enfrentar a pobreza. Por isso, o Programa Bolsa Família serviu como um dos determinantes da amostragem que selecionou os sujeitos pobres a partir do mesmo critério estabelecido pelo Estado. 
A lógica do PBF se constituiu no acesso a uma renda mínima, decorrente de critérios e compromissos de inclusão social, ou seja, a concessão do benefício deveria estar associada à oferta de serviços básicos existentes nos municípios, para possibilitar emancipação e autonomia às famílias pobres.

Para tanto, este estudo teve como problemática central: Quais são as representações sociais dos sujeitos que vivem em condição de pobreza e sua interferência ao desenvolvimento no Planalto Norte Catarinense? O objetivo do estudo foi analisar as representações sociais dos sujeitos que vivem em condição de pobreza no Planalto Norte Catarinense.

Para que os propósitos do estudo fossem alcançados, a organização dos conteúdos mostra, dialeticamente, a realidade social e nela o cenário da pobreza. Em seguida, fundamenta-se teoricamente os termos centrais da pesquisa: pobreza, exclusão e representação social. Na sequência apresenta-se o discurso do sujeito coletivo com reflexões acerca dessa complexa temática.

\section{METODOLOGIA}

O estudo foi desenvolvido sob procedimentos metodológicos da abordagem qualitativa, tendo como aporte os tipos de pesquisa exploratório e explicativo. Processou-se estudos teórico-conceituais pela pesquisa bibliográfica.

Para a pesquisa de campo foi delineada uma amostra de beneficiários do PBF dos municípios de Mafra, São Bento do Sul, Irineópolis e Três Barras, com recorte de gênero, ou seja, mulheres com filhos (mães inscritas no Cadastro Único - Cadiúnico - e beneficiárias do PBF, que se encontrassem envolvidas com as atividades promovidas pelo Serviço de Convivência e Fortalecimento de Vínculos (SCFV) nos Cras dos municípios. Como critério de inclusão utilizou-se a assinatura do Termo de Consentimento Livre e Esclarecido (TCLE).

Tabela 1 - Amostragem para a pesquisa de campo

\begin{tabular}{|c|c|c|c|}
\hline $\begin{array}{l}\text { Municípios partici- } \\
\text { pantes do estudo }\end{array}$ & $\begin{array}{l}\text { Participantes do en- } \\
\text { contro no dia da cole- } \\
\text { ta de dados }\end{array}$ & $\begin{array}{l}\text { Participantes bene- } \\
\text { ficiários convidados } \\
\text { para participar }\end{array}$ & $\begin{array}{l}\text { Participantes bene- } \\
\text { ficiários que aceita- } \\
\text { ram participar }\end{array}$ \\
\hline São Bento do Sul & 52 & 49 & $31(63,26 \%)$ \\
\hline Mafra & 48 & 41 & $36(87,80 \%)$ \\
\hline Irineópolis & 33 & 25 & $18(72 \%)$ \\
\hline Três Barras & 40 & 35 & $30(85,71 \%)$ \\
\hline \multicolumn{3}{|c|}{ Total de sujeitos que aceitaram participar do estudo } & 115 \\
\hline
\end{tabular}

Fonte: Dados do estudo (2014).

A pesquisa de campo foi orientada por um roteiro contemplando questões semiestruturadas, aplicadas por ocasião dos encontros do grupo de mães no SCFV, reunidas às quartas-feiras, situados no Centro de Referência da Assistência Social (Cras) nos municípios de São Bento do Sul, Mafra, Irineópolis e Três Barras. O roteiro era compos- 
to por 7 questões e a coleta de dados ocorreu em local definido pela entrevistada. A entrevista tinha duração média de 30 minutos, sendo gravada após autorização das participantes da pesquisa de campo e os discursos coletados foram transcritos na íntegra.

Para a reflexão e explicação dos dados utilizou-se a análise do discurso do sujeito coletivo (DSC) (LEFÈVRE; LEFÈVRE; TEIXEIRA, 2000). Os questionamentos realizados apresentaram respostas das entrevistadas bastante semelhantes entre si e entre as amostragens dos quatro municípios nos quais foi realizada a pesquisa de campo. O material foi organizado e analisado conforme se apresenta adiante.

\section{REPRESENTAÇÕES SOCIAIS DA POBREZA: Da Realidade à Teoria e ao Discurso dos Sujeitos}

\section{A Realidade Social da Pobreza no Planalto Norte Catarinense}

A problemática da pobreza apresentou-se na trajetória da humanidade e por isso Ihe deu certo entendimento de naturalização, mas a pobreza pode ser entendida sob diversos aspectos, desde privação material, fome, baixa qualidade de moradia. Também essa problemática tem alcançado patamares cada vez mais elevados em todo o mundo e no Brasil nas últimas décadas vem se observando cada vez mais desigualdade na distribuição de renda (SILVA; BANDEIRA; LOPES, 2011).

Em se tratando dos termos econômicos, a pobreza foi reconhecida como a falta ou inadequação de renda. Em termos sociais a pobreza pode estar envolvida com o isolamento na comunidade e o sentimento de baixa autoestima (VINHAS, 2006). Para os sujeitos pobres em uma sociedade capitalista, o não ter emprego ou ter um trabalho mal-remunerado, que não permite satisfazer as suas necessidades básicas, não atinge apenas o bem-estar biofisiológico, mas afeta os sujeitos com a sensação de inutilidade e de incapacidade de se realizar, sensação esta que impede os indivíduos de usufruírem dos bens socialmente construídos.

Com esse indicativo recortado da amplitude dos estudos e pesquisas sobre pobreza, focou-se na problemática da exclusão que perpassa as reflexões, principalmente aquelas relacionadas com a miséria e a fome, em países-nações potencialmente ricos quando este cenário se constituiu um paradoxo, que reflete nas representações sociais dos sujeitos.

Conforme Silva e Barros (2007), a pobreza pode ser perceptível em diversos lugares e situações. Captar sua dimensão é complexo e subjetivo, uma vez que ela apresenta multidimensionalidade, podendo ser explicada de forma absoluta, relativa e subjetiva.

Um dos parâmetros mais conhecidos para a determinação da pobreza e que indica a sua forma extrema foi apresentado pelo Banco Mundial. Para este organismo, pobres extremos são os que vivem com menos de 1 dólar por dia. Este parâmetro é criticado por atender a uma visão limitada da problemática, ou seja, mensura renda e consumo na perspectiva econômica, não considerando que a pobreza vem se mostrando cada vez mais multifacetada. 
Em complemento aos critérios e situações da pobreza e da pobreza extrema no Brasil, o IBGE (BRASIL, 2010) identificou predominância da população nestas condições localizada no meio rural e nos Estados do Nordeste brasileiro, os quais concentravam a maior parte dos sujeitos extremamente pobres (9,61 milhões) (BRASIL, 2010).

A partir da definição do Índice de Desenvolvimento Humano (IDH), criado pela Organização das Nações Unidas (ONU) para avaliar a qualidade de vida e o desenvolvimento econômico da população, o Brasil manteve-se no ranking mundial no 85임 lugar, apresentando o IDH de 0,73 (PNUD, 2013).

As reflexões acerca de cenários e determinações em torno de pobre e pobreza respaldaram uma diretriz nacional referendada na Constituição Federal brasileira (1988), a qual expõe, nos seus princípios fundamentais, artigo 3으, inciso III, o objetivo de erradicar a pobreza e a marginalização, reduzindo as desigualdades sociais (BRASIL, 1988). Com essa direção social, no Brasil vem se desenvolvendo uma política pública com políticas sociais, constituídas a partir de campos multidisciplinares, em que a Política Social de Assistência Social vinculou-se mais diretamente ao cenário da pobreza e exclusão. Nesta direção, as intervenções ocorreriam por meio de programas previstos para enfrentar e reduzir a fome, a pobreza e a desigualdade social.

Vinculada ao fenômeno da pobreza, emergiu um campo de investigação, a exclusão social, que foi historicamente produzida no país deste a época do Brasil Colônia, a qual passou a ser mais observada a partir da década de 70. Nesse período a pobreza era basicamente relacionada ao crescimento econômico brasileiro.

Sendo assim, estudar a pobreza fez-se e se faz sempre relevante para o entendimento dos fins sociais demandados pela garantia dos direitos universais. Isso posto, o estudo delimitou uma região, na qual os índices de pobreza, referendados pelos relatórios oficiais, demarcavam a presença marcante da pobreza e da exclusão social. No Planalto Norte Catarinense, constituído por 13 municípios, foram selecionados dois municípios com o maior IDHM (São Bento do Sul e Mafra) e dois com o menor IDHM (Irineópolis e Três Barras).

Quadro 1 - Representação da pobreza nos municípios estudados

\begin{tabular}{|l|c|c|c|c|}
\hline & $\begin{array}{c}\text { São Bento do } \\
\text { Sul }\end{array}$ & Mafra & Três Barras & Irineópolis \\
\hline IDHM & 0,76 & 0,73 & 0,70 & 0,69 \\
\hline População Municipal - habitantes & 74.801 & 52.912 & 18.129 & 10.448 \\
\hline Cad Único $^{1}$ & 4.293 & 6.991 & 3.177 & 1.377 \\
\hline Pobreza Extrema & 527 & 1.021 & 647 & 479 \\
\hline Programa Bolsa Família & 1.126 & 1.643 & 1.047 & 685 \\
\hline $\begin{array}{l}\text { Benefício Social de Pobreza Extrema } \\
\text { (BSPE) }\end{array}$ & 169 & 306 & 649 & 42 \\
\hline BPC-Idosos & 251 & 157 & 30 & 25 \\
\hline BPB - Pessoas com Deficiência & 335 & 398 & 88 & 137 \\
\hline
\end{tabular}

Fonte: BRASIL (2014). 
Ao se observar os dados constantes no Quadro 1 verifica-se que o município de São Bento do Sul continha cerca de $1,5 \%$ da sua população beneficiária do PBF. No município de Mafra havia cerca de $3,10 \%$ da sua população na condição de beneficiária do PBF. Por outro lado, no município de Três Barras 5,77\% de sua população era beneficiária do $\mathrm{PBF}$, enquanto em Irineópolis os beneficiários do programa atingiam $6,55 \%$ de sua população.

Com esse cenário social concreto, buscou-se encontrar fundamentação teórica para explicar a(s) concepção(ões) de pobreza no discurso dos sujeitos beneficiários do PBF na região pesquisada.

\section{A (Re)Significação de Pobreza}

Nesse contexto a (re)significação de pobreza pode expressar-se por meio de muitas formas e seu crescente desenvolvimento pode ser acompanhado no mundo todo (CRESPO; GUROVITZ, 2002). Daí a importância de se entender e explicar a problemática que se faz presente também no recorte regional do Planalto Norte Catarinense.

Pelas abordagens que descreveram a pobreza, em especial mais ao final do século 20, três novas concepções foram desenvolvidas: (1) a concepção de sobrevivência, (2) de necessidades básicas e (3) de privação relativa.

A concepção da sobrevivência (séculos 19 e 20 até a década de 50) esteve relacionada à renda do mais pobre e à manutenção do rendimento físico de um indivíduo, cujo pressuposto de fundo dizia respeito ao individualismo compatível com o ideário da teoria liberal. Sob este enfoque e medidas estatísticas, formulou-se o primeiro modelo de proteção social para o Estado de bem-estar fundamentado em políticas nacionais de assistência (SILVA; BARROS, 2007).

Em seguida, a partir de 1970, novas exigências como serviços de água potável, saneamento básico, saúde, educação e cultura passaram a ser consideradas necessidades mínimas para a sobrevivência e por esta razão a pobreza recebeu conotação relacionada com as necessidades básicas (PEREIRA-PEREIRA, 2000).

Nos anos de 1980 a pobreza passou a ser entendida como privação relativa, que introduziu aos estudos da, e sobre a, pobreza, variáveis mais amplas que a conduziram para um entendimento de que os sujeitos podem sofrer privações em diversas esferas da vida, não implicando somente a privação material e que estas privações sofridas pelas pessoas determinavam o seu posicionamento em todas as esferas sociais (CRESPO; GUROVITZ, 2002).

No enfoque do estudo desenvolvido, porém, tomou-se como uma das explicações da (re)significação de pobreza de Silva e Barros (2007), que afirma que uma das possibilidades de se entender e explicar a pobreza seriam as suas expressões objetiva ou subjetiva. A primeira expressão referia-se às manifestações concretas do fenômeno na vida dos pobres, por outro lado, a dimensão subjetiva da pobreza dizia respeito a como o fenômeno era percebido pela sociedade em geral, inclusive pelos próprios sujeitos da pobreza.

Complementa essa direção explicativa de pobreza no estudo desenvolvido a abordagem da pobreza como fenômeno multidimensional, que provocou discussões para um entendimento de pobreza de forma complexa. Alerta-se que no contexto dessa 
abordagem existiam outras contribuições, tais como as culturalistas; as estruturalistas; as liberais-neoliberais, conforme Silva (2004)), as quais foram estudadas, mas que na direção deste texto foram excluídas.

A abordagem multidimensional definia a pobreza a partir de três esferas que se inter-relacionam: a pobreza como juízo de valor, a pobreza relativa e a pobreza absoluta (SILVA; BARROS, 2007). Para Crespo e Gurovitz (2002, p. 3) a pobreza como juízo de valor comportava a visão subjetiva e abstrata do indivíduo, do que deveria ser um grau suficiente de satisfação de necessidades, ou do que deveria ser um nível de privação normalmente suportável. Estes mesmos autores definiram a pobreza relativa relacionada com a desigualdade na distribuição de renda, sendo aquela situação em que o indivíduo, quando comparado a outros, tem menos renda, logo, mais condições desfavoráveis de emprego ou poder. Na sequência Crespo e Gurovitz (2002) abordaram o enfoque da pobreza absoluta como um instrumento para a concepção de intervenções do Estado, que fixou padrões para o nível mínimo ou suficiente de necessidades dos indivíduos. Este padrão foi conhecido como linha ou limite de pobreza, determinando o percentual da população situada abaixo desse nível.

Com a explicação dessas bases teórico-conceituais, avançou-se no estudo no sentido do discurso dado. Considerou-se como recorte de identificação da condição de pobre ou extremamente pobre os critérios de inclusão social do PBF.

\section{A Representação Social - Pobre e Pobreza}

É importante destacar que mais uma concepção que respalda o estudo com os sujeitos pobres (beneficiários do PBF) do Planalto Norte Catarinense denominou-se de representação social. ${ }^{3}$

Para enunciar uma sucinta trajetória histórica acerca das representações sociais, desde seus precursores e nos últimos 40-50 anos, recorreu-se a Alves-Mazzotti (2008, p. 21), o qual define representações sociais destacando que nas sociedades modernas o cotidiano é um imbrincado composto de conhecimentos e informações colocadas diante dos sujeitos, de modo que das interações se concebam "universos consensuais".

Este estudo e pesquisa sobre representações sociais dos sujeitos pobres da região do Planalto Norte Catarinense tomou por base a Teoria das Representações Sociais (TRS), que emergiu na década de 60, decorrente de estudos do psicólogo romeno (radicado na França) Serge Moscovici. O estudo das representações sociais no estudo da pobreza, portanto, tornou-se um ponto relevante na complexa e ampla base referencial sobre pobreza, que se alastrou nas décadas mais recentes. Assim, essa teoria (a das representações sociais) possibilitaria a investigação das maneiras que os sujeitos e grupos sociais entendem a sua realidade social.

\footnotetext{
A psicologia social aborda as representações sociais no âmbito do seu campo, do seu objeto de estudo, da relação indivíduo-sociedade e de um interesse pela cognição, embora não situado no paradigma clássico da psicologia. Esta abordagem se reflete sobre como os indivíduos, os grupos, os sujeitos sociais, constroem seu conhecimento a partir da sua inscrição social, cultural, de forma a se compreender como a sociedade se dá a conhecer e constrói esse conhecimento com os indivíduos.
} 
Para Moscovici (1978, p. 26), representação social seria "uma modalidade de conhecimento particular que tem por função a elaboração de comportamentos e a comunicação entre indivíduos". Assim sendo, as representações sociais seriam conjuntos dinâmicos que provocam a produção de comportamentos e relações como meio de modificar o outro, de forma lógica, própria, em uma linguagem particular, não se transformando em opiniões sobre objetos ou imagens, mas sim em teorias ou ciências coletivas que se destinam à interpretação da realidade atual.

Desta forma o estudo das representações sociais provocou uma releitura do saber popular, do conhecimento do cotidiano e do conhecimento pré-teórico, ${ }^{4}$ de forma que o conhecimento sobre a realidade tornou-se socialmente construído. Esta construção deu-se a partir do saber do sujeito interligado com a sua inscrição social. A isso Moscovicci (1978) deu o nome de processo social (apud ARRUDA, 2002). Para aquele autor, processo social tratava-se de um processo de familiarização pelo qual os objetos e os indivíduos poderiam ser compreendidos e distinguidos na base de modelos ou encontros anteriores. A predominância do passado sobre o presente, da resposta sobre o estímulo, da imagem sobre a realidade tinha como única razão fazer com que ninguém encontrasse nada de novo sob o sol. A familiaridade constituía-se ao mesmo tempo em um estado das relações no grupo e uma norma de julgamento de tudo o que acontecia. Considerando então que o entendimento de pobreza relacionava-se a algum tipo de privação, seja ela material, cultural ou social, diante dos recursos disponíveis para um sujeito, entendeu-se a necessidade de exploração desse universo complexo e contraditório campo de conhecimentos férteis e de relevante significação expressado em um discurso manifestado pela linguagem, o que se propôs na realização desta pesquisa.

\section{RESULTADOS E DISCUSSÕES}

Conforme exposto na metodologia, a amostragem da pesquisa de campo foi de 115 mulheres. Elas tinham idades entre 18 e 63 anos e residiam nos municípios de São Bento do Sul, Mafra, Irineópolis e Três Barras. Foi possível mostrar que essa população assemelhava-se à de outras regiões com segmentos pobres. Quanto à escolaridade das entrevistadas, $50,43 \%$ delas possuía o 1 o grau incompleto, $40,86 \%$ tinha estudado o 1 o grau completo, 7,82\% tinha avançado para o 20 grau, mas era incompleto e nenhuma entrevistada tinha concluído o 2 ㅇau, fosse técnico ou profissionalizante.

Outra questão identificou a relação das participantes do estudo com o mercado de trabalho. Das 115 mulheres entrevistadas 23,47\% encontravam-se inseridas no mercado de trabalho informal, já 76,53\% relataram encontrar-se fora do mercado de trabaIho, fosse ele formal ou informal. Nenhuma das entrevistadas era vinculada ao trabalho formal.

\footnotetext{
${ }^{4}$ Conhecimento que advém da ciência, trata-se de uma concepção Teoria do Conhecimento, a qual considera a observação da realidade, enquanto um ponto de intersecção entre verdade e senso comum, para tentar entender como o conhecimento é construído (BERGER ; LUCKMANN, 1996).
} 
Devido ao fato de o estudo tratar de famílias beneficiárias do Programa Bolsa Família e os sujeitos tratarem-se de mães, levantou-se também o número de integrantes nas famílias estudadas. Foi possível constatar então que 33,91\% das entrevistadas viviam em famílias compostas com até 3 integrantes, 45,21\% em famílias compostas por 4 ou 5 integrantes e 20,86\% com famílias com 6 ou mais integrantes.

No que se refere à renda das pesquisadas, identificou-se que $66,95 \%$ delas possuíam renda familiar de 1 salário mínimo; 33,05\% tinham renda inferior a 1 salário mínimo e nenhuma das entrevistadas declarou viver com renda superior a 1 salário mínimo.

Com relação ao foco do estudo mesmo, o questionamento realizado sobre o entendimento (representação social) do que seria pobreza, as entrevistadas (mulheres, mães, beneficiárias da transferência de renda do Programa Bolsa Família) se posicionaram nas entrevistas. Para apresentar recortes das falas totais que representassem o significado exposto pelas entrevistadas, utilizou-se uma forma de categorização, a qual se denominou discurso- síntese. Após ter se definido esse discurso-síntese, utilizou-se uma ferramenta do Word para localizar nos textos que transcreviam as manifestações das entrevistadas e se realizou os recortes localizados como uma amostragem extraída da totalidade dos conteúdos dos DSC a seguir apresentados. Assim, para o Sujeito 25 (São Bento do Sul), bem como para os demais citados a seguir, a sua representação social sobre pobreza seria: "pobreza é não ter nada e não ver saída desta situação; é tão difícil de dizer que nem consigo colocar tudo que penso; imagine, é tudo de ruim que você possa imaginar [...]". Para o Sujeito 7 (Mafra): "pobreza é ver meus filhos sentindo a mesma dificuldade que eu senti quando era criança; é ter que repetir para eles o que eu ouvia da minha mãe ("isso não é coisa para pessoas pobres"); hoje repito para minhas filhas; para mim pobreza é a falta de tudo; é a necessidade de ter que depender das outras pessoas (dinheiro, roupa, comida)". Também para o Sujeito 11 (Irineópolis): "é a falta de dinheiro; sem dinheiro falta todo o resto, não se tem comida, roupa nova, coisas para oferecer para seus filhos; acho que tudo se resume em falta de tudo... até de esperança [...] o meu mundo é muito diferente do seu"; e Sujeito 3 (Três Barras): "pobreza é ser visto de forma diferente pelas pessoas, sentir vergonha por não conseguir ser melhor do que o dia de ontem e saber que os próximos amanhãs serão todos iguais, sem dinheiro, sem trabalho, sem vida digna; me sinto preso a esta condição". A ideia síntese sobre estes significados do Discurso do Sujeito coletivo, diante do questionamento do que vinha a ser pobreza, foi de que pobreza é a falta de tudo, dinheiro, esperança, é ter que depender de outras pessoas, é sentir vergonha de ser visto diferente pela sociedade.

Neste sentido, o discurso-síntese indicou que a pobreza é não ter dinheiro. "Não conseguir oferecer melhores coisas para seus filhos, é depender da ajuda de outras pessoas sempre. É sentir que se é tratado de forma diferente pela sociedade, muitas vezes deixado de lado, quando as oportunidades vão ficando cada vez mais difíceis de serem encontradas; isso só faz com que sejamos mais pobres. Até parece que ser pobre é bom, e que não queremos melhorar; as pessoas com mais dinheiro devem pensar que não queremos crescer como elas, até queremos, mas não temos as mesmas oportunidades, o nosso mundo é diferente, não se tem a mesma liberdade de quem tem dinheiro". 
Foi possível observar nos depoimentos que a pobreza também é compreendida pelo sujeito entrevistado a partir de uma leitura multidimensional, pela qual a falta de dinheiro, e os recursos adquiridos com ele, muitas vezes é apresentada como primeira condição de pobreza. Verifica-se, no entanto, o reconhecimento da falta de oportunidade, da indiferença social e liberdade, como restrições provocadas pela pobreza.

Freire (2011) descreve que a abordagem multidimensional da pobreza poderia ser definida como privação de capacidades, ou seja, privação de liberdade de escolha entre diferentes alternativas de modos de vida e este fator poderia impedir as pessoas pobres de conduzirem sua vida possuindo razões de valorização.

Já o autor Amartya Sen (2000) compreendia a pobreza de forma mais completa, descrevendo-a como uma ausência de funcionamento (habilidade de realizações) e de capacidades (liberdade para realizar), propondo principalmente que a pobreza não deve ser vista como uma questão apenas econômica e individual, mas sim como um conceito social, de forma que ela possa ser analisada a partir de estados e ações humanas.

Desta forma, pôde-se identificar no discurso do grupo pesquisado a ausência de liberdade de escolha, fator que as mantinha na condição de pobreza, pois elas poderiam até escolher não serem sujeitos pobres. Principalmente as condições a que se encontravam expostos os privava da liberdade de simplesmente mudar de vida, ao buscarem oportunidades (fator presente no discurso individual de muitas entrevistadas); faltava-Ihes espaço e aceitação na sociedade.

Santos (2007) descreveu que a pobreza, quando definida como privação de capacidades, acabou por refletir na liberdade das pessoas. Já Sen (2000) classificou três razões distintas para liberdade; (1) a que por si só gera bem-estar; (2) a que permite a realização de funcionamentos relevantes para o bem-estar e (3) a que possibilita ao indivíduo realizar a condição de agente social. Desta forma a privação de liberdade pode contribuir para o empobrecimento dos sujeitos.

Quando a reflexão dos pesquisados voltou-se à existência da pobreza, esses indicaram que ela teria na falta de estudo o principal provocador da ausência de oportunidade. Este direcionamento no discurso poderia ser relacionado com dados já identificados nas características demográficas apresentadas, as quais mostraram percentual de 91,29\% das entrevistadas que possuem escolaridade de até o 1 o grau concluído.

Pontili (2004) destacou que ocorreram pesquisas realizadas na área da economia e os resultados apontaram para a importância da escolaridade como fator desencadeador da melhoria da qualidade de vida das pessoas. Deve-se considerar então que a educação, ao compor um dos direitos fundamentais do sujeito, é um preparo para o exercício da cidadania e para a qualificação para o trabalho (BRASIL, 1998).

Percebeu-se no discurso dos sujeitos participantes do estudo que a falta de escolaridade é um fator provocador da falta de oportunidades, principalmente de trabalho na sua vida, quando $11,30 \%$, além de assumirem essa condição, repassaram a responsabilidade ao Estado, que não Ihes oferecia melhores condições de vida e principalmente pelas alterações do mundo e no mercado de trabalho. Em complemento, $88,70 \%$ das entrevistadas se autor- responsabilizaram pela sua condição, ou seja, no discurso coletivo identificou-se uma relação dessa condição à escolaridade. 
Essa autorresponsabilidade foi evidenciada pelas entrevistadas ao dizerem que: SIC "sou pobre porque não estudei, nunca gostei da escola desde pequeno e meus pais não me mandavam ir, isso fez com que eu desistisse muito cedo (estudei até a 5a série), pois achava que ir para a escola era perda de tempo, naquela época eu gostava mesmo de brincar, depois o tempo foi passando, passei a trabalhar nas casas para ter um dinheirinho, e quando comecei buscar serviço de verdade, vi que devia ter estudado mais, e que ia ser difícil ter um trabalho bom" (Sujeito 22 município de Mafra); "quando vi que devia ter estudado mais para conseguir trabalho, voltei a estudar, estas escolas especiais, mas não consegui acompanhar. Hoje não consigo trabalhar registrada, pois não tenho a oitava série e não adianta, não consigo aprender as coisas, já estou muito velha" (Sujeito 11 São Bento do Sul); e, SIC "sem estudo não tem trabalho, sem trabalho não tem dinheiro, sem dinheiro sou pobre" (Sujeito 3 Irineópolis).

No mesmo instante em que as entrevistadas se autorresponsabilizavam pela sua condição, indicavam elementos dessa condição, também demonstravam que existia a possibilidade de saírem da situação de pobreza atual, ou seja, 90,43\% das entrevistadas expressaram que o enfrentamento e superação da condição de pobreza é possível. Vale destacar uma amostragem desses discursos: SIC "existe possibilidade sim, mais depende de muita coisa, voltei a estudar, também estou participando de alguns cursos profissionalizantes oferecidos pela prefeitura, queria ter certeza que é só isso, para que eu possa trabalhar registrada e daí possa ser feliz, sem me preocupar se amanhã vou ter dinheiro para comprar comida ou roupa para meus filhos, vou andar na rua de cabeça erguida, me sentindo igual a todo mundo" (Sujeito 12 município de Mafra); SIC “já estou fazendo meus filhos irem para escola, não deixo perder um dia, se meus pais tivessem feito isso comigo talvez eu estivesse melhor de vida, mas agora não dá para olhar para traz, tenho que olhar para frente e não deixar que meus filhos tenham a mesma vida que eu" (Sujeito 8 Três Barras)

Foi possível observar nos discursos individuais apresentados anteriormente algumas estratégias que já estavam sendo utilizadas visando ao enfrentamento da situação de pobreza, mas as entrevistadas manifestaram suas buscas pela liberdade de escolherem em que condições quereriam viver. Isso pôde ser identificado nos discursos dos sujeitos do município de Mafra, Três Barras e São Bento do Sul, quando apontaram alternativas tais como voltar a estudar e a se inserirem em cursos profissionalizantes oferecidos pelos Programas de Fortalecimentos de Vínculos. Também concebiam um projeto de vida familiar, ou seja, a manutenção dos filhos na escola poderia fazê-los sair da condição de pobreza, uma forma de inclusão social.

Ainda sob enfoque de Amartya Sen, foi possível analisar nos discursos apresentados que a necessidade desses sujeitos contém entendimento de liberdade para usufruírem e realizarem aquilo que pode agregar inclusão e transformações, neste caso a inclusão social seria proveniente da potencialização de sua vida pelo trabalho como reconhecimento social. Esta afirmativa converge com a abordagem seniana, na qual a liberdade é considerada intrinsecamente importante por enriquecer a vida humana, a 
partir do favorecimento de oportunidades da pessoa ter resultados e participação social (FREIRE, 2011). Santos (2007) complementa igualmente que a expansão da liberdade deveria ser vista como principal fim ${ }^{5}$ e principal meio ${ }^{6}$ para o desenvolvimento.

A pesquisa indagou às entrevistadas sobre o que poderia contribuir para que saíssem da situação em que se encontravam. Delineando o DSC, o exposto sobre o que poderia contribuir para que as entrevistadas pudessem direcionar o seu movimento para o enfrentamento e superação da condição de pobreza, foi manifestado da seguinte forma: Sujeito 23 (S. Bento do Sul): "mais emprego"; Sujeito 21 (Mafra): "mais oportunidade de trabalho digno; não é por que sou pobre que não posso ter um trabalho bom, em um lugar limpo, parece que as pessoas esperam que os pobres façam o trabalho ruim e o rico o trabalho bom; agora estou trabalhando em lugar ruim porque ainda estou estudando, ainda sou pobre, mas quero ir trabalhar em um lugar bom"; Sujeito 2 (Irineópolis): "duas coisas, mais trabalho e melhorar a renda do benefício, pois é muito baixa e não dá para fazer muita coisa; tenho 5 filhos para dar de comer e vestir todo mundo, não é barato" e Sujeito 18 (Três Barras): "mais oportunidade para trabalhar; na medida que as pessoas vejam que com o trabalho dá para deixar de ser pobre e começarem a trabalhar e não ficar dependendo só de ajuda as coisas melhoram. Vejo muita gente que mora perto da minha casa que fica esperando a ajuda cair do céu; veja, tenho 4 filhas, meu marido foi embora... o que eu posso fazer, buscar trabalho para dar coisas para elas e ensinar elas serem diferentes ou ficar em casa esperando ajuda igual a muita gente e ensinar minhas filhas fazer a mesma coisa amanhã".

O discurso síntese dessa questão extraída do DSC delineou-se para mais oportunidade de trabalho, o que seria o percurso eficaz para a superação da pobreza. Ou seja, advindo do DSC foi possível refletir que esses sujeitos atribuem ao trabalho, com o qual poderia obter renda, o recurso estratégico do enfrentamento da pobreza e de sua condição de ser pobre.

Esta relação pode acontecer devido ao sentimento de privação, ou seja, o recurso obtido do trabalho escasso ou inexistente ocasiona privações. Entendem que a falta de renda as leva à falta de outras condições. Como a renda - dinheiro - tem uma relação direta com o trabalho, entendiam que seria por meio do trabalho que obteriam renda e, por conseguinte, melhores condições e menos privações.

Albuquerque (1995) observa que passou a existir uma dependência familiar relativamente grande da renda da mulher e das chefes de família e esta dependência ocorria principalmente a partir da subutilização da força de trabalho familiar.

O apontamento desse autor foi apropriado para relacionar aos vínculos dos integrantes do grupo familiar com trabalho formal ou não formal. Nesta questão transpareceu: os sujeitos dos discursos e seus familiares eram beneficiários do Programa Bolsa

\footnotetext{
5 papel constitutivo está associado às liberdades substantivas, que incluem a capacidade de evitar a fome, a subnutrição, doenças que podem ser prevenidas, morte prematura, bem como as liberdades associadas à instrução, à participação política, à liberdade de expressão, etc. As liberdades substantivas devem ser consideradas importantes independentemente do interesse individual em exercê-las ou não: mesmo que uma pessoa não tenha vontade de exercer sua liberdade de expressão, por exemplo, seria uma privação se ela não pudesse ter a escolha por manifestar-se ou não. Essas liberdades são parte integrante do enriquecimento da vida humana. (SANTOS, 2007, p. 38).

${ }^{6}$ Já as liberdades instrumentais são importantes na medida em que contribuem para promoção de outros tipos de liberdades (liberdade política, facilidades econômicas, oportunidades sociais, garantia de transparência e segurança protetora), que se inter-relacionam entre si, permitindo uma liberdade global do sujeito (SANTOS, 2007).
} 
Família, os vínculos com trabalho eram precários ou inexistentes; 76,53\% das entrevistadas relataram encontrarem-se fora do mercado de trabalho, seja ele formal ou informal; a concentração da renda entre as entrevistadas era de menos de 1 a 1 salário mínimo; ainda que o conhecimento delas sobre as estratégias de inclusão social por meio de políticas sociais e respectivos programas (neste caso a questão focou apenas a esfera local - município), 80,87\% dos participantes da pesquisa responderam que saíram da situação de pobreza por meio do PBF.

No escopo das representações sociais das entrevistas sobre pobreza e sua condição de vida, mesmo não sendo um dos elementos centrais do estudo, a melhoria de sua condição de vida após a inclusão em um programa social levantou que para as entrevistadas na sua totalidade o PBF foi o programa social. Levou a interpretar que se a renda é o fator primordial para boas condições de vida, esse programa seria o redentor de sua condição de pobreza, como foi possível constatar nos discursos dos sujeitos. Sujeito 16 (S. Bento do Sul): "pude comprar mais coisas, não são muitas, mas já dá para oferecer o mínimo para meus filhos, de vez em quando trabalho de faxineira e já entra um pouco mais de dinheiro ( $R \$ 50,00 \mathrm{dia}$ ), com isso atendo às necessidades da minha família"; Sujeito 29 (Mafra): "consegui melhorar algumas coisas em minha casa, comprei TV, uma cozinha nova, fico muito feliz quando estou em casa e vejo que as coisas estão melhorando, bem devagar, mas há 5 anos atrás eu morava de favor no quartinho de uma amiga, tinha uma pia e dois colchões, hoje tenho até TV, sou muito feliz"; Sujeito 2 (Irineópolis): "consigo comprar as coisas, pouquinhas, mas não falta mais comida, o restante as outras pessoas ajudam, com roupas que não usam mais, ou móveis que iam jogar fora, é assim que eu vou conseguir as coisas. O Bolsa Família me ajuda com a comida necessária para a sobrevivência, tomara que eu nunca perca" e Sujeito 18 (Três Barras): "como melhorei, não preciso mais dizer não para tudo que meus filhos precisam; me sinto mais importante quando vou no mercado e consigo comprar e pagar minhas compras, sinto que não devo nada para ninguém, me sinto mais digna".

Como ideia central desses discursos pôde-se extrair: aquisição de bens materiais, dignidade e autonomia, portanto, como discurso-síntese, pode-se afirmar que o PBF ajuda muito. Por meio dele puderam acessar utensílios e equipamentos para suas residências e em especial suprir as necessidades mínimas de seus filhos. Em especial, porém, há um destaque sobre a autoestima quando a entrevistada atribui ao fato de ter uma renda e sustentar a família, um episódio de reconhecimento, pois conseguia sustentar sua família sem a necessidade da caridade. Isso foi identificado quando, em discursos individuais, destacaram-se essencialmente a aquisição de alimentos, roupas e bens materiais. A percepção de melhoria na condição de vida, após ter acessado o benefício do Programa Bolsa Família, no discurso incide autonomia e no sentimento de dignidade.

Pela análise respaldada em Sen (2000) relacionou-se este sentimento de dignidade e autonomia com a liberdade exposta por este autor. Sen (2000) identificou a liberdade relacionada por meio de três principais formas: a pobreza econômica, a carência de serviços públicos e assistência social e a negação de liberdade política e civil. 
Pode-se identificar que a inclusão destas famílias no PBF amenizou a ausência de dois dos tipos de liberdades propostos por Sen (2000): a liberdade provocada pela pobreza econômica, caracterizada pela ausência de recursos econômicos (que impede a aquisição de bens essenciais como alimento, moradia, vestuárioł.

Ainda, um segundo tipo de liberdade - política e civil - que se caracterizou pela restrição da participação das pessoas em determinados grupos sociais ou econômicos. Identificou-se que as pessoas beneficiadas pelo PBF são estimuladas a participarem mais ativamente na sociedade em que vivem. Um dos discursos de entrevistada manifestou que "hoje não tenho vergonha de andar na rua; sempre que recebo aproveito para comprar as coisas que estão faltando, e faço isso me sentindo importante, igual às outras pessoas" (SIC).

A partir do discurso dos sujeitos pesquisados para este estudo, quando perguntados sobre o que é pobreza, do porquê existem pessoas nesta condição, quais fatores contribuíram para que a condição dessas pessoas fosse esta, de que forma o Estado contribui para a superação desta condição, pôde-se constatar como discurso-síntese que ocorreram melhorias a partir do momento em que foram incluídos em programas sociais de erradicação à pobreza, e havia uma possível relação entre a pobreza dos sujeitos pesquisados para o estudo e as condições da região que vivem.

\section{CONSIDERAÇÕES FINAIS}

Concluídas as etapas do trabalho foi possível tecer reflexões finais a partir da indagação do estudo, sobre as representações sociais dos sujeitos que vivem em condição de pobreza. Confirmou-se que, na região pesquisada a problemática da exclusão e da pobreza integra o cenário da realidade social. Particularidades dessa realidade podem ter contribuído para a constituição e consolidação desse quadro de exclusão e pobreza.

A região do Planalto Norte Catarinense é remanescente das explorações madeireiras e ervateiras que lhes deu certo destaque, como uma das maiores produtoras da erva-mate no passado. Já no setor madeireiro, foi a extração dessa riqueza natural, que foi um dos estopins da Guerra do Contestado, que marcou a identidade de exploração e espoliação do trabalhador desses segmentos produtivos. Desses trabalhadores se necessitava os braços fortes para o trabalho rude. Sem formação ou estudo, mas que se submetessem às condições perversas do trabalho, cujos traços dessa forma de produzir são evidenciados ainda hoje. Mesmo que a era do extrativismo, como é denominado aquele período, tenha diminuído, a identidade cultural que, por conseguinte, é um enfoque entre as concepções de pobreza, reproduziu e mantém uma posição do trabalho de subserviência, de subalternização.

Reitera-se que a composição do cenário produtivo da região não foi objetivo da pesquisa mais amplamente desenvolvida, mas não se pode menosprezar que as representações sociais dos sujeitos coletivos (DSC) (LEFRÈVE; LEFÈVRE; TEIXEIRA 2000) retrataram as interferências desse cenário, uma vez que na exposição das entrevistadas as representações sobre a sua condição de pobreza foram relacionadas com o fator produtivo apenas na questão do trabalho e renda. Isto é, os sujeitos pobres manifestaram entendimento de que se permaneciam pessoas nesta condição, a justificativa não seria outra a não ser a falta de estudo, o que leva à ausência de oportunidade de trabalho digno. 
Os dados da empregabilidade do grupo pesquisado, da condição de beneficiárias do PBF, bem como a denúncia da sobrevivência pelo trabalho informal, corroboraram que há intensos enfrentamentos para o Estado e para a sociedade civil, que deveriam historicamente promover as estratégias de intervenção sobre as questões que cada segmento demanda.

É evidente que as políticas públicas e seus programas promoveram impacto, mas este pode-se resumir à transferência de renda, uma vez que o não alcance do processo gerador do cenário da exclusão e pobreza levou as entrevistadas a se autorresponsabilizarem pela condição em que se encontravam. Esse discurso foi corroborado pela dimensão subjetiva da pobreza que, conforme apontado por Silva e Barros (2007), ao tratar da (re)significação de pobreza, uma das possibilidades de se entender e explicá-la seriam as suas expressões objetiva ou subjetiva. A dimensão subjetiva da pobreza, nesse sentido, diz respeito a como o fenômeno é percebido pela sociedade em geral, inclusive pelos próprios sujeitos da pobreza. Ou seja, a trajetória da formação da classe trabalhadora, nas várias etapas da construção do processo de desenvolvimento, em particular do produtivo nacional, reproduzido na região do PNC, fez o que o melhor do capitalismo soube fazer: a exploração e a alienação, marcando que o referencial explicativo da pobreza seria intercorrência da pobreza sob o enfoque objetivo, segundo Silva e Barros (2007).

Em complemento, mas sob a perspectiva da pobreza objetiva, seria uma manifestação concreta do fenômeno na vida dos pobres, ou seja, a falta de estudo e a falta de oportunidade de trabalhar com retorno que os colocassem em uma condição de estabilidade e de bem-estar, foi a relação direta que o discurso dos sujeitos revelou. Ambos os aspectos mencionados dizem respeito a um dos principais vetores da sociedade produtiva brasileira, ou seja, a educação utilitarista e a serviço do capital.

Isto é, sob o fundamento dos estudos teóricos, a leitura do discurso manifestado sobre a possibilidade de os sujeitos saírem dessa situação referendou o enfoque unilateral, ou seja, retomando os estudos, com capacitações para responder aos atuais ordenamentos do sistema produtivo. Confirmou-se, portanto, a relevância das intervenções das políticas públicas como respostas aos dilemas da sociedade brasileira, constituídas quase em meados do século 20. Isto posto, não causa estranheza que as pesquisadas, beneficiárias no PBF, não tenham conseguido identificar outras intervenções das políticas públicas além daquelas no âmbito do Programa de Atenção Integral à Família (Paif) e do SCFV desenvolvido nos Cras dos respectivos municípios.

A oportunidade de trabalho digno, como manifestado nos discursos, revelou um tênue lampejo de igualdade, no entanto a exclusão por ter sido relacionada aos dois aspectos (educação e trabalho) manifestou a falta de entendimento que sua condição poderia ser decorrente da pobreza multidimensional.

Retomando elementos para a explicação para essa reduzida apreensão da condição de pobreza vista pela representação social de si, aquela pode ser confirmada pelas explicações que se apresentou neste texto. O estudo trouxe uma perspectiva da pobreza a partir do enfoque da privação de capacidades básicas, quando a renda insuficiente para as necessidades básicas mínimas seria um fator reconhecido como uma das principais causas da pobreza, porém não a única, o que retoma o enfoque da pobreza multidimensional. 
Pelo exposto nos discursos, a pobreza foi amplamente assumida pelas entrevistadas com o sentido da privação de liberdade. Se a renda fosse suficiente seria um recurso estratégico de autonomização dos sujeitos, mas como há inexistência ou insuficiência de renda, esta situação foi relacionada com a dependência e com a ausência de liberdade de escolha.

Quando se volta à região e ao desenvolvimento do Planalto Norte Catarinense, foi possível extrair dos discursos que os sujeitos conseguem fazer uma relação do seu desenvolvimento pessoal com o desenvolvimento de seu lugar - município. Ficou evidente nos discursos das entrevistadas quando relacionaram a pobreza com a ausência de oportunidades, realidade observada onde vivem. Por ora reconhecem que a pobreza seria a realidade social, dado que reconheciam a mesma condição de si em outras pessoas na mesma região. Ao mesmo tempo, destacaram que o fato de serem beneficiárias da transferência de renda do PBF as colocou em condição melhor do que a de outras pessoas. Haveria, então, alguma inclusão social.

Logo, pôde-se considerar diante dessa manifestação que as entrevistadas sentiam-se atendidas em suas demandas. Analisando o contexto da pobreza regional, porém, era preciso destacar que isso estaria mais vinculado a uma inclusão comunitária e social. Para as entrevistadas isso já seria a superação de uma etapa nas suas vulnerabilidades. Isto seria para elas uma sensação de liberdade para suas escolhas.

Concluiu-se então que os aspectos que favoreceriam o desenvolvimento da região também estariam relacionados com a sensação de liberdade de escolhas e de envolvimento social de seus sujeitos, permitindo que estes se identificassem ativos no processo de autodesenvolvimento com o desenvolvimento de sua região.

Os indicativos dos discursos foram conclusivos em aspectos das subjetividades, abrindo precedente para a investigação das práticas sociais nas quais se envolveriam ou no modo como agiriam de forma mais emancipada. Novos desafios sobre a pobreza e seus desdobramentos teórico-conceituais, bem como dos desdobramentos das representações sociais não reveladas, continuariam as reflexões acerca da pobreza e as implicações no desenvolvimento regional.

Para sustentar as possíveis explicações acerca dessas implicações, de posse dessa realidade social (representações sociais de e da pobreza pelas pessoas legalmente reconhecidas como pobres ou extremamente pobres), aspectos teriam de ser considerados.

No âmbito do local e no trato cotidiano do enfrentamento da pobreza, a visão parcial e subjetiva, assentada na relação desenvolvimento como crescimento econômico, precisa ser reposicionada, sob o fundamento do desenvolvimento como direito fundamental.

A base do desenvolvimento concebido neste estudo referiu-se a uma composição de dimensões (econômicas, sociais, políticas, culturais, ambientais), dialética e historicamente produzidas. Os seus desdobramentos têm se mostrado tendencialmente vinculados a uma construção de setores e de classes, nas quais se situam os sujeitos históricos, em relações sociais e de poder que também historicamente falsearam a concepção de igualdade, consolidando a desigualdade social, na qual a pobreza é a parte 
mais perversa de sua manifestação. Haveria, pois, vários desdobramentos dessas dimensões que poderiam explicar o modo como os amálgamas necessários e os existentes impulsionariam um ir adiante, na superação da pobreza.

Uma sociedade comporta setores, segmentando o modo de produzir, de viver e de se estabelecer relações sociais. Estas, quando o desenvolvimento se tornou apenas a dimensão econômica, gerou relações de poder que ameaçaram o bem-estar e a dignidade humana.

Nesse contexto, mesmo com o arcabouço legal, o Estado e os governos (neo)liberais distorceram o aparato da inclusão social e da emancipação humano-social, o que marcou estágios incipientes de desenvolvimento. Os discursos desses sujeitos coletivos - governantes - contradizem o caráter da igualdade e da justiça social que transversa a renda mínima e, por conseguinte, a transferência de renda.

No bojo das representações sociais amplas, a transferência de renda pelo Programa Bolsa Família carrega consigo a equivocada compreensão de um paternalismo alienador que serviria para manter o pobre pobre e reproduzindo pobreza. Esse discurso disseminado não revela que a transferência de renda é uma forma de travessia, pela qual o beneficiário é compensado pela trágica e histórica exclusão que a desigualdade social constituiu.

De fato e como dever legal, o Estado deveria se ocupar dessa construção educativa e política da sociedade que carrega consigo o respaldo do Estado Democrático de Direito e dos fundamentos da cidadania e da dignidade da pessoa humana (CFB de 1988, artigo 1ㅇ). Pobreza e pobreza extrema não convergem com essa diretriz social brasileira. O enfrentamento da exclusão passa pela superação da pobreza e haverá implicações no desenvolvimento escalar e dimensional (local, regional, humano, social, sustentável) se a pobreza continuar reproduzindo e intensificando a desigualdade social.

\section{REFERÊNCIAS}

ALBUQUERQUE, Roberto Cavalcanti de. Estratégia de desenvolvimento e combate à pobreza. Revista Estudos Avançados (IEA-USP), São Paulo, v. 9 n. 24, maio/ago. 1995. Disponível em: www.iea.usp.br/revista. Acesso em: 10 set. 2013.

ARRUDA, A. Teoria das representações sociais de gênero. Cadernos de Pesquisa, Rio de Janeiro, v. 1, n. 117, p. 127-148, 1으. nov. 2002. Disponível em: http://www.scielo.br/pdf/cp/n117/15555.pdf. Acesso em: 16 out. 2013.

ALVES-MAZZOTTI, A. J. Representações sociais: aspectos teóricos relacionados a educação. Múltiplas Leituras, Rio de Janeiro, v. 1, n. 1, p. 29-45, 10 jul. 2008. Disponível em: https://www.metodista.br/revistas/ revistas-ims/index.php/ML/article/viewFile/1169/1181. Acesso em: 20 out. 2013.

BERGER, Peter L.; LUCKMANN, Thomas A. A construção social da realidade: tratado da sociologia do conhecimento. Petrópolis: Vozes, 1996.

BRASIL. Instituto Brasileiro de Geografia e Estatística (IBGE). Censo 2010. 2010. Disponível em: http:// www.ibge.gov.br/home/estatistica/populacao/censo2010/calendario.shtm. Acesso em: 16 out. 2013.

BRASIL. Instituto de Pesquisa Econômica e Aplicada (Ipea). Erradicação da pobreza no Brasil. Disponível em: www.ipea.gov.br. Acesso em: 10 jul. 2014.

BRASIL. Ministério do Desenvolvimento Social (MDS). Programa Bolsa Família - como funcional. Disponível em: http://mds.gov.br/assuntos/bolsa-familia/o-que-e/como-funciona. Acesso em: fev. 2013 e fev. 2017.

BRASIL. Constituição da República Federativa do Brasil, de 5 de outubro de 1988. 1988. Disponível em: https://www.planalto.gov.br/ccivil_03/constituicao/constituicaocompilado.htm. Acesso em: 12 dez. 2017. 
CRESPO, A. P. A.; GUROVITZ, E. A pobreza como um fenômeno multidimensional. Rae - Eletrônica, São Paulo, v. 1, n. 2, p. 1-12, 30 jul. 2002. Mensal. Disponível em: http://www.scielo.br/pdf/raeel/v1n2/ v1n2a03.pdf. Acesso em: 7 jul. 2013.

FREIRE, L. de C. Pobreza multidimensional: uma aplicação às unidades federativas brasileiras. 2011, 72 p. Monografia (Curso de Ciências Econômicas) - Universidade Federal Fluminense, Niterói, 2011.

LEFÈVRE, F.; LEFÈVRE, A. M. C.; TEIXEIRA, J. J. V. O discurso do sujeito coletivo: uma nova abordagem metodológica em pesquisa qualitativa. Caxias do Sul: Educs, 2000.

LUCKMANN, Thomas (ed.). Phenomenology and Sociology: selected readings. Penguin Books. 1978.

MOSCOVICI, S. La Psychanalyse, son image, son public. Paris: PUF, 1961.

MOSCOVICI, S. A representação social da psicanálise. Rio de Janeiro: Zahar, 1978.

MOSCOVICI, S. Comunicação apresentada ao Colóquio sobre as representações sociais. EHESS, Paris, p. 8-10, jan. 1979.

OLIVEIRA, M S. B. S. de. Representações sociais e sociedades: a contribuição de Serge Moscovici. Rev. Bras. Ci. Soc. [on-line], 2004, vol. 19, n. 55, p. 180-186, 2004. ISSN 0102-6909. http://dx.doi.org/10.1590/ S0102-69092004000200014.

PAUGAM, S. A desqualificação social: ensaio sobre a nova pobreza. Trad. Camila Giorgetti, Teresa Lourenço. São Paulo: Educ; Cortez, 2003.

PEREIRA-PEREIRA, P A. Necessidades humanas: subsídios à crítica dos mínimos sociais. São Paulo: Cortez Editora, 2000.

PONTILI. R. A infra-estrutura escolar e as características familiares influenciando a freqüência e o atraso no ensino fundamental. Piracicaba: Esalq; USP, 2004.

PNUD. Programa das Nações Unidas Para o Desenvolvimento. Desenvolvimento Humano e IDH. Disponível em: http://www.pnud.org.br/IDH/DH.aspx. Acesso em: 12 maio 2013.

ROCHA, S. Pobreza no Brasil: afinal do que se trata. Rio de Janeiro: FGV, 2006. 244 p.

SANTOS, L. M. N. Pobreza como privação de liberdade: um estudo de caso na favela do Vidigal no Rio de Janeiro. 2007. 191 p. Dissertação (Mestrado em Economia) - Pós-Graduação em Economia, Universidade Federal Fluminense, Niterói, 2007. Disponível em: http://www.bdtd.ndc.uff.br/tde_arquivos/40/TDE2008-02-11T131509Z-1261/Publico/2007-larissa_martins.pdf. Acesso em: 21 maio 2014.

SEN, A. K. Desenvolvimento como liberdade. São Paulo: Companhia das Letras, 2000.

SILVA, M. O. S. e. O debate sobre a pobreza: questões teórico-conceituais. In: Revistas de Políticas Públicas, São Luís: Universidade Federal do Maranhão, Unidade de Pós-Graduação em Ciências Sociais, v. 6, n. 2, p. 65-102, jan./jun. 2000.

SILVA, L. P. V. Pobreza e suas formas de resistência e enfrentamento no Município de Belágua - MA. 2004. Dissertação (Mestrado) - Universidade Federal do Maranhão, Programa de Pós-Graduação em Políticas Públicas, São Luís, 2004.

SILVA, L. M.; BARROS, S. M. In: JORNADA INTERNACIONAL DE POLÍTICAS PÚBLICAS, 3., Bolsa Família-Estratégia de Enfrentamento a Pobreza no Brasil. São Luiz, 2007. Anais [...] Maranhão. São Luís, MA: Ufma, 2007. p. 1-8. V. 1. Disponível em: http://www.joinpp.ufma.br/jornadas. Acesso em: 25 ago. 2013.

SILVA, A. C.; BANDEIRA, E. S. F.; LOPES, E. B. In: JORNADA INTERNACIONAL DE POLÍTICAS PÚBLICAS, $5 .$, Aspectos conceituais e o processo de construção histórica. Pobreza no Brasil. 2011, São Luís. Anais [...] São Luís, MA: Ufma, 2011. p. 1-9. V. 1. Disponível em: http://www.joinpp.ufma.br/index.php. Acesso em: 10 ago. 2013.

VINHAS, H. E. F. Ensaio sobre a redução da pobreza no Brasil: mensuração e determinantes. 2006. $158 \mathrm{f}$. Dissertação (Mestrado) - Universidade de São Paulo, Curso de Economia, São Paulo, 2006. Disponível em: www.teses.usp.br. Acesso em: 10 jul. 2013. 